\title{
CONCEPTUAL MODEL OF 3D ASSET MANAGEMENT BASED ON MYSPATA TO SUPPORT SMART CITY APPLICATION IN MALAYSIA
}

\author{
Amalin A'ishah Mohd Nasir ${ }^{1}$, Suhaibah Azri ${ }^{1}$, Uznir Ujang ${ }^{1}$ and Zulkepli Majid ${ }^{1}$ \\ 13D GIS Research Group, Geoinformation, Faculty of Built Environment and Surveying, Universiti Teknologi Malaysia, 81310 \\ Johor Bahru, Johor, Malaysia
}

aaishah2@live.utm.my; suhaibah@utm.my,mduznir@utm.my, zulkeplimajid@utm.my

Commission VI, WG VI/4

KEY WORDS: 3D Asset Management, MySPATA, CityGML, Smart City, 3D City Model and Asset Maintenance

\begin{abstract}
:
Urbanization is the access to modernization and development around the world. Nowadays, with the current technology development, smart cities are seen as a new approach in urban management and development. 3D asset management is one of the components to support the idea of smart city. 3D asset management is important to assist the monitoring and maintenance of asset in smart city by enabling visualization of 3D models, locating and query in real-time based. In Malaysia, the government is looking seriously at the issues of asset management and maintenance. This is happened because asset management in present day is already moving towards the revolution of smart city but still considered as time consuming and open to human errors as the asset managers or authorities still considering on paper-dependent and manual inspection practise. In the past few years, Malaysia has developing an electronic-based asset management, MySPATA that is made prior to the inefficiency on the asset management system. MySPATA has been introduced as electronic based asset management solution for immovable assets that belong to various department and ministries. However, the creation of MySPATA is considered as bland and time-consuming as its application only storing and displaying asset information. Thus, the implementation of 3D asset management is required for a better and effective management. In this paper, we proposed the conceptual model of 3D asset management by incorporating with the new CityGML standard. The proposed 3D asset management is based on MySPATA module. CityGML plays an important role in demonstrating the 3D asset management for modelling, string and exchanging city models in the international standard. So, the 3D asset management is developed based on MySPATA module that integrated with new CityGML concept. Therefore, with this new approach and concept, the managing of assets will lead for better management and maintenance.
\end{abstract}

\section{INTRODUCTION}

In recent years, the world is facing a rapid urban development. The acceleration in the urban development happens around the world because of the rising of population and demand. Moreover, the fourth industrial revolution has bolstered development in every industries including urbanization. A smart city concept has been introduced suitable for this new revolution. A smart city is a political initiative based on a sustainable development strategy and aims to improve the life quality of citizens (Lafioune and StJacques, 2020). Smart cities utilize modern digital technology to solve problems while managing resources efficiently and Smart cities are usually understood to provide network services that work across departments to retrieve data and to organize it into understandable and useful information (AssetWorks, 2018).

A geographic information system (GIS) has been used in the construction of a large-scale model of a smart city project (Shahrour, 2018). Geographical information system (GIS) is an application of gathering, managing and analysing data. Geographical information system (GIS) is playing an important role in smart city concept. The geographic information system (GIS) offers advanced and user-friendly capabilities for smart city projects (Shahrour, 2018). GIS was fundamentally created as a framework for catching, putting away, questioning, dissecting and showing geologic-referenced information yet with the headway in the web, portable innovation, GIS rose as a wide term and a total bundle which can allude to various present day advances and propel forms and turns out to be more standard that grows learning of the urbanization and associations among individuals (Naidu, 2018). GIS is a platform to helps governments with the tools to develop smart cities and provides better services to the community. Cities are complex agglomerations of houses and buildings, streets and roads, parks, neighborhoods, shopping centers, and industrial plants (Wenwen $\mathrm{Li}, 2020)$. Therefore, this complex information of the cities need the help of a geographic information system (GIS) to facilitate the data collection and management of information on the cities.

This model for smart cities with open and connected spatial data allows everyone from planners to managers to the public understand what needs to be done, and access the proper tools and resources to achieve those goals (Barry, 2018). The collaboration of the GIS and Smart Cities help to share spatial data in building more organised organisation. One of the important why GIS is being used for the Smart Cities development is that GIS enable to have collaboration with realtime location tools that enable everyone can access the information and stay up-to-date about the condition and management of the cities. Moreover, GIS also helps to accomplish 3D representation of Smart Cities as its tools enable to handle and visualize 3D geometry spatial data. The 3D representation in GIS is used for more realistic representation of the real world objects. Thus, Geographical Information System (GIS) is also one of the key for smart city development.

The 3D asset management is one of the applications that is related to the Smart City approach. Smart Cities has a wide range of definitions across the industry with lots of promises are being made on technology that can achieve ambitious outcomes (Martin, 2019). At the same time, the technologies advancement and the rapid increased usage of information technology (IT) 
application make the smart city more practical and convenient for our current urban populations. Advanced urban analytics can be done to understand the city surroundings (Azri et al., 2018; Azri et al. 2016). In the past, asset management is usually managed and stored as paper-dependent and manual inspection practise. This practise is time-consuming and prone to human error. Therefore, to overcome this shortcoming, the managing of assets must be integrated with the current technology approach which is $3 \mathrm{D}$ visualization. $3 \mathrm{D}$ visualisation can be seen as an alternative to perceive real world scenario before making any decision or action (see Yusoff et al., 2011)

Moreover, the $3 \mathrm{D}$ asset management is developing a new and smarter buildings and infrastructures. If one is looking straight into the significance of asset management, it keeps city operations running smoothly (SmartCity, 2020). Intelligent 3D asset management is becoming more commonplace particularly on public sector projects. 3D modelling describes the process of building data from the design process to the creation of the $3 \mathrm{D}$ model of the actual building or structure. The 3D model can demonstrate how a building or structure might perform. This visualization on $3 \mathrm{D}$ enable the monitoring and maintenance of building and its structure (see Akula et al., 2013). Knowing how infrastructure and buildings are going to perform throughout the design life, this will enable authorities to be proactive rather than reactive in managing that assets (Wessing, 2017). The asset management is essential for smart city as facing challenges in managing city assets. The examples of challenges in managing city are road or highway maintenance, building monitoring and so on. From these challenges, integrated information system has been realized as a key to overcome the challenge. Thus, the application will bring more benefits for managing the city assets.

Asset management refers to systematic approach to the governance and realization of value from the things that a group or entity is responsible for, over their whole life cycles (Wikipedia, 2020). The development of the 3D asset management is the integrated between $3 \mathrm{D}$ models and information of assets. It is necessary to update the asset management process by utilizing existing technologies (Saptari et al., 2019). The needs of 3D models are expanding rapidly in variety of fields nowadays. The integration between $3 \mathrm{D}$ models and asset management will be an application that will help in better management.

The $3 \mathrm{D}$ asset management forms a major discussion in this paper. The remaining of this paper discusses the related work of study in Section 2, the new CityGML standard in Section 3, MySPATA and managing assets in Section 4 and finally conclusion.

\section{RELATED WORK}

The publications related to the asset management is covering a large scope. A variety of asset management research has been conducted along the years which has shown that asset management is an important part of application especially for government or any asset management organizations.

Some researchers have been focusing on studying and developing application that are suitable for asset management system. Aslam and Haron (2018) have conducted a research involving the intelligent Building Information Modelling (BIM) record model for effective asset management of constructed facilities. The research has proposed a model that is capable of solving interoperability issues since the database has been designed with an open-BIM format (IFC). Moreover, this model can help in developing database that can be used for asset management during operation and maintenance life cycle. Moreover, some researchers are conducting a management of semantic 3D city models for the next generation of CityGML that can be useful for managing assets. Chaturvedi, Smyth, Gesquire, Kutzer and Kolbe (2016) have been focusing on the concept and data model extending CityGML by denoting versions of models or model elements as planning alternatives. This approach facilitates the interoperable integration and exchange of different version of a 3D city model within one dataset, including possible complex history of a repository. The advantages of the approach is that not only it facilitates the data model for supporting different version, but also allows the different versions of a repository within one dataset.

Lastly, a research conducted by Aziz, Hashim and Baharum in 2013 involves some issues about space inventory in Malaysia due to the inaccurate data, lack of centralized data management and ineffective methods or system implemented. In this research, the database of space inventory management has been highlighted as an essential to assist organization to plan and manage their physical asset. To overcome the problem, they have implemented the Government Immovable Asset System (MySPATA), to introduce and standardize the government asset management. Thus, in this section, related works that have been reviewed were carefully described to show different aspects of study conducted that are related to the management of assets. The researches in related works help to introduce the concept that show the advantages and benefit of the study for future research. In this paper, a new concept will be explained in details.

\section{3D ASSET MANAGEMENT AND CITYGML}

Asset is a resources with economic value that individual, corporation, or a country owns or control with expectation that it will provide a future benefits (Berone, 2020).Asset management is a systematic process of developing, operating, maintaining, upgrading, and disposing of assets in the most cost-effective manner (including all costs, risks and performance attributes) (Wikipedia, 2020). The concept of asset management is not new but it is an evolving idea that has been developed and gaining attention of many agencies. Asset management is applying the principle of engineering, business management, and economic through computer aided technologies (Dewan, 2004).

Asset management tools and technologies provide the fundamental strength to enable organizations to make informed decisions (Leong, 2005). These tools and technologies enable organisations to effectively practice good asset management such as:

1. Quantifying current infrastructure holdings - what do we own and where it is.

2. Qualitatively analysing infrastructure holdings - what condition is it in, what level of service is it providing, what is it the capacity and functionality.

3. Analysing performance - how was the infrastructure performed in the past.

4. Planning - short-term plans for routine maintenance, medium term plans for pro-active maintenance and long term plans for periodic maintenance.

5. Analysing the whole life of infrastructure to determine best investment strategies and maintenance practices.

Figure 1 shows the life cycle of the asset management. There are eight steps involve in this life cycle includes:

1. Careful need of identification (people who will operating or using the asset) 
2. Planning what is expected from it once acquired

3. Design specification needed

4. Procurement or building based on the previous steps

5. Commissioning or properly installing to make sure get everything in purchase contract

6. Operating, maintaining and monitoring the asset on continual basis

7. Modifying the asset or upgrading it if possible and if this makes a good commercial sense

8. Decommissioning or disposing of the asset so that it can be appropriately replaced.

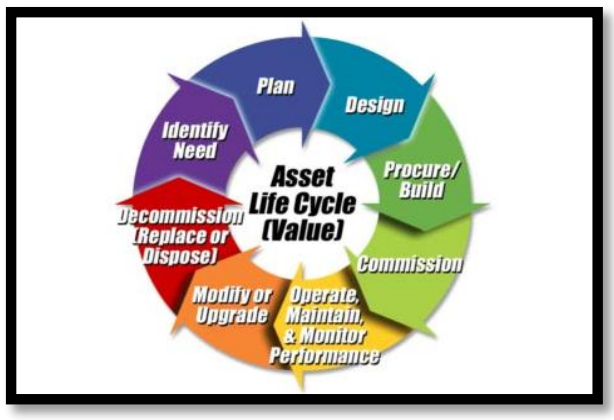

Figure 1: The Asset Life Cycle Management (Source: blog.readytomanage.com)

There are three important concepts in understanding asset life cycle management (Warner, 2014):

1. Asset management is not a "general: approach but one in which every important asset managed on an asset-by-asset basis and over its whole life from pre-purchase to disposal.

2. In order to maximize the value of the assets, the organization need to tract the activities related to the assets throughout their life cycles, to make sure they align with the organization's ongoing strategic and operational objectives.

3. In that context, a total asset management life cycle approach is a total to track the activities of each asset, provide the data for the organization to analyze the use of that asset and compare the data gathered against the intended goals.

\subsection{CityGML Overview}

The implementation of 3D asset management is not new (see Pan et al., 2013). However, the recent development of City Geography Markup Language (CityGML) makes it possible for integration. CityGML is an application of independent geospatial information model for semantic 3D City and landscape models. The focus of CityGML is on the semantical aspects of 3D city models, its structures, taxonomies and aggregations, allowing users to employ virtual 3D city models for advanced analysis and visualization tasks in a variety of application domains such as urban planning, indoor/outdoor pedestrian navigation, environmental simulations, cultural heritage, or facility management (Groger et al., 2012; Salleh and Ujang, 2018;). Besides, CityGML can comprise different thematic areas such as building, vegetation, water, terrain, traffic, tunnel, bridges and more. CityGML represents 3D geometry, 3D topology, semantics and appearance(Kolbe, 2019).

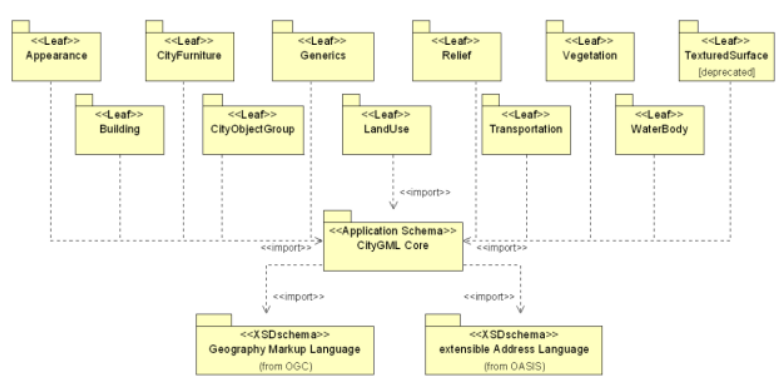

Figure 2: Module of CityGML and their scheme dependencies (Source: Groger et al., 2008)

There are a few versions of CityGML such as CityGML 1.0, CityGML 2.0 and the new standard CityGML 3.0. As for version 1.0 of CityGML standard, possible subsets of the data model are defined and embraced by so called CityGML modules (Groger et al., 2008). The CityGML is consists of a core module and thematic extension modules. The core module defines the basic concept and component of CityGML data model. Meanwhile, there are eleven thematic extension modules are introduced by version 1.0 of CityGML standard. The eleven extension modules are Appearance, Building, City Furniture, City Object Group, Generics, Land Use Relief, Transportation, Vegetation, Water Body and Texture Surface. Figure 2 shows the module of CityGML.

Moreover, CityGML 2.0 is the major revision of the previous version of CityGML 1.0. This version 2.0 introduces substantial additions and new features to the thematic model of CityGML. The main endeavor of the revision process was to ensure backward compatibility both on the level of the conceptual model and on the level of CityGML instance documents (Groger et al., 2012). Following are an overview of what's new in CityGML 2.0:

1. New thematic modules for representation of bridges and tunnels

2. Additions to existing thematic modules (CityGML core module, Building Module, Generic module, land use module, and all modules)

3. Additions to the CityGML code list mechanism

\subsection{The CityGML New Module}

In the CityGML 3.0 includes a new space concept, a revised level-of-detail (LOD) concept, the representation of time dependent properties, the possibility to manage multiple versions of cities, the representation of city objects by point clouds, an improved modelling of construction, the representation of building units and storey, an improved representation of traffic instructure as well as clear separation of the conceptual model and data encoding that allows for providing further encoding specification besides GML. The CityGML 3.0 standard will consist of two parts: The CityGML 3.0 Conceptual Model specification, which is planned to be released on the early 2020 , and the CityGML 3.0 GML Encoding specification, which is to be published a couple of month after. The CityGML 3.0 Conceptual Model defines seventeen modules as shown in Figure 3. 


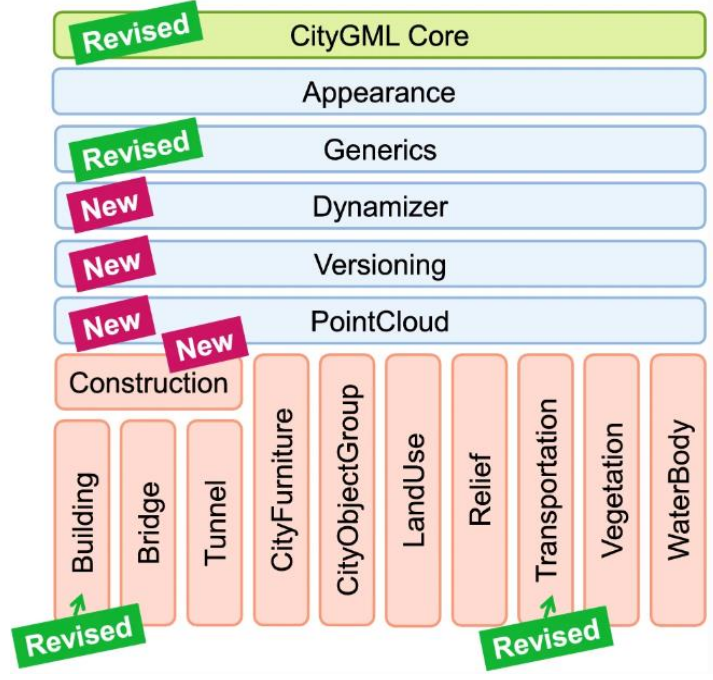

Figure 3: CityGML 3.0 overview

(Source: Kutzer et al., 2020)

Based on this newly revised module, this research will be focused on the refinement of Constructions and Building. CityGML 3.0 will contain a new Construction module that defines concept of common to all kinds of man-made construction likes building, bridges, and tunnels (Janecka, 2019). However, this research will be highlighted more on the Building Module. The Building module introduces as a new class AbstractBuildingSubdivition, which is modelled as subclass of AbstractLogicalSpace, and the two specialisation Building Unit and Storey to allow for the represention of building unit (like apartments) and storeys (as shown in Appendix A). This is to facilitate more direct mapping of IFC into CityGML. This feature allows mapping constructive elements from BIM data sets given in the IFC standard onto CityGML. The IFC standards are the IFC classes IfcWall, IfcRoof, IfcBeam, IfcSlab and so on.

Furthermore, in this research, Space Module is also included together with Building Module. In the Space Module, a clear semantic distinction of spatial features is introduced by mapping all city objects onto the semantic concepts of spaces and space boundaries. A Space is an entity of volumetric extent in the real world (Janecka, 2019). Volumetric extent is existed in building, water bodies, trees, rooms, and traffic spaces. Hence, in modelling, they usually be modelled as space or also known as specific subclasses of abstract class space. Moreover, Space Boundary is an entity with areal extent in the real world and the characteristic of Space Boundary is as delimit and connect Spaces such as wall surfaces and roof surfaces that bound to the building.

Besides, the spaces can be further subdivided into physical spaces and logical spaces. Physical Spaces are spaces that fully or partially bounded by physical objects. For instance, Building and rooms are the known as physical spaces as they are bound by walls and slabs. While for Logical Spaces, they involved spaces that are not necessarily bounded by physical objects but according to thematic considerations. For example, a building unit is a logical space that aggregates specific rooms to flats, the rooms that have physical spaces that are bounded by wall surfaces, whereas the aggregation as a whole is being delimited to virtual boundary. In CityGML 3.0, a physical space is classified into Occupied Spaces and Unoccupied Spaces. Occupied spaces represent physical volumetric objects that occupy space in urban environment and in contrast, unoccupied spaces represent physical volumetric entities that do not occupy space in urban environment(Kutzner et al., 2020). So in this research, the concept of Building will be integrated with the Spaces, in instance, the building and building furniture will have identified as occupied spaces meanwhile building rooms and traffic spaces will be identified as unoccupied spaces as shown in Figure 4.

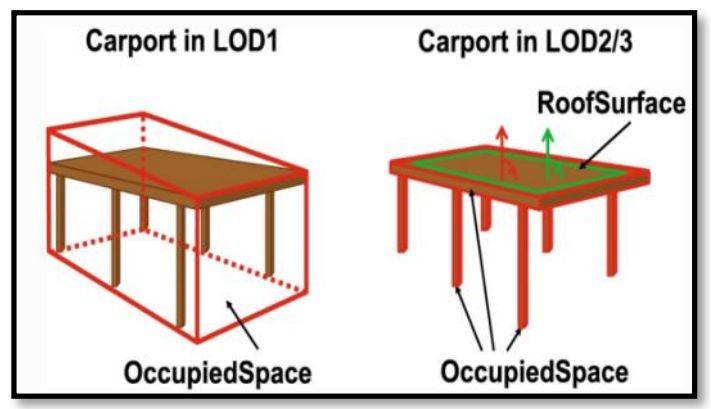

Figure 4: Occupied and Unoccupied Space (Kutzer et al., 2020)

Then, in the classification of feature types into Occupied Space and Unoccupied Space also define the semantics of geometries attached to the respective features. For examples, Building and Furniture; these will have an impact on the required orientation of surface normal that attach to thematic surfaces. For Occupied Spaces, the normal vectors of thematic surfaces must point in the same direction as the surfaces of the outer shell of volume as in contrast for Unoccupied Spaces, the normal vectors of the thematic surfaces must point in the opposite direction as the surfaces of the outer shell of the volume (Kutzner et al., 2020). The differences between the Occupied Space and Unoccupied Space might be apparent at first sight. This can be shown in example in Figure 5.

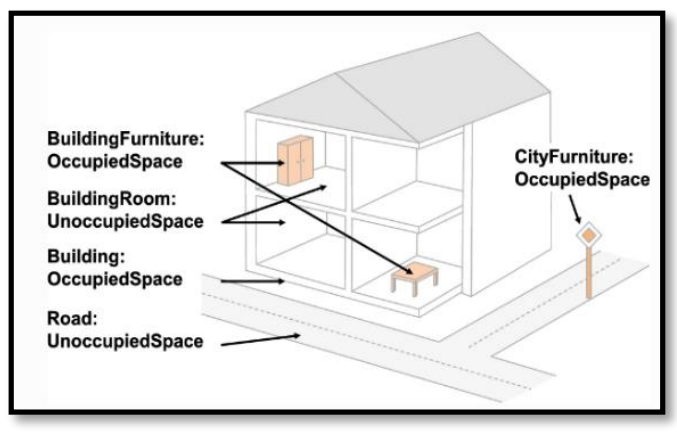

Figure 5: Representation of a carport as Occupied Space in different LODs. (Kutzer et al., 2020)

The carport, as shown in Figure 5 is the representation as Occupied Space. The Carport is not closed and most of the space is free of matter. Carports are represented as buildings in cadastres. As the carports are roofed, the immovable structure will be proposed as to provide shelter to the objects such as cars. So, in this research, a carport is as example of occupied space that should be modelled in CityGML as instance of class Building. In addition, in the figure above, has shown the representation of the carports as the occupied space in different LODs. The red boxes represent solids and the green area represents a surface. Meanwhile, the normal vectors of the roof are shown in red and in contrast, the roof surface is shown in green. From the explanations, only in LOD1, the entire volumetric region covered by the carport will be considered as physically occupied while in LOD2 and LOD3, the solid represents more realistically of physical occupied 
space of carport. Thus, for all Occupied Spaces, in instance of Roof Surface, the normal vector needs to point away from the solids.

\section{MySPATA and Managing Asset}

MySPATA is the Government Immovable Asset Management System. MySPATA is developed by Malaysian Administrative Mordenisation and Management (MAMPU) in collaboration with Malaysian Public Works Department (JKR). This is a government initiative to enable systematic, efficient and integrative asset management(Arifin, 2020). MySPATA has to be introduced as the electronic based asset management solution for all categories of immovable assets belong to various departments and ministries (Devision, 2019).The existing of this system is in line with the government policy that requires all assets to be properly registered and managed. The function of the system is:

1. Establish effective and efficient management of immovable asset information to improve the level of Government service delivery.

2. Ensure that assets management is implemented systematically, holistically and sustainably to achieve optimal asset benefits.

3. Ensures easier implementation of valuation and monitoring of immovable assets.

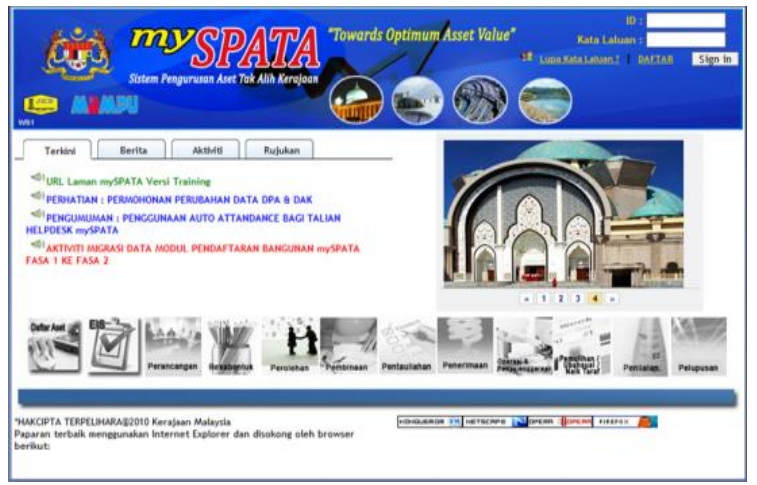

Figure 6: The interface of MySPATA (Source: MySPATA Manual Guide)

Figure 6 shows the main interface of MySPATA (JPAK, 2018). For login, the ID and password are required. Besides, on the main interface, there are also Now, News, Activities and References tab. Moreover, in MySPATA application, there is an user hierarchy until the fifth level. This is because the MySPATA application allows all users from different agencies and government section. This hierarchy has been shown in Figure 7 below.

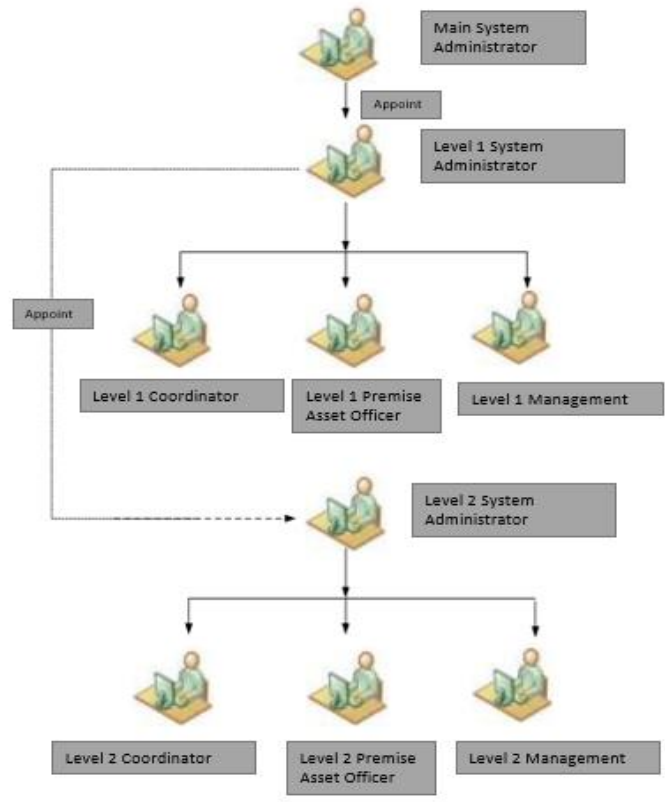

Figure 7: Example of User Hierarchy (Source: MySPATA Manual Guide)

\subsection{D Database Design Based on MySPATA}

In 3D application, the initial step for visualization 3D models is by producing a database design. An efficient way to manage 3D data is needed since 3D data complexities requires fast retrieval database design (Azri et al. 2014). Database design is the process of producing a detailed data model of database that contains all of the needed logical and physical design choices. The demand of serving large 3D spatial data, mainly of urban areas, reflects the need of hierarchical data structures for 3D data (Koukofikis et al., 2018). To design the database, the relationship between data elements and logical structure are determined. In this paper, the database is designed based on Malaysia asset management system that is known as MySPATA. The example of database design has been shown in Figure 8. The information on the database is based on user requirement analysis.

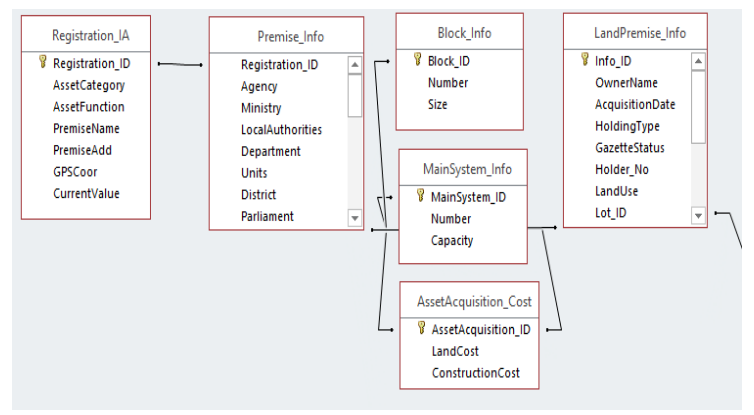

Figure 8: Example of Database design based on MySPATA.

In MySPATA application, the information that are related to the asset management are Assets Registration and Information, Land Registration, Buildings and Infrastructure Registration and Information and any related information. From this, the database design will interpolate the information from MySPATA to a new concept of asset management application. In database design, a class shall be created onto one table where each tables containing 
attributes that represent an object of respective class. Each of the table should have at least one Primary key column. Additional columns are added for storing spatial and non-spatial attributes for respective class objects. Besides, in additional column, a Foreign key is added as a relationship between the main tables and additional tables.

In this study, the data is categorized into spatial data and attribute data. The Spatial data was referred to the 3D model of the assets and attribute data is the description and information for each asset recorded based on user requirement analysis (URA). The Spatial data used in this study is 3D model of assets, terrestrial laser scanning and Unmanned Airborne Vehicles (UAV) for 3D data capture. Meanwhile, the attribute data was referred to the description about the asset record. The attribute data of assets was stored in a database in Microsoft Access. Then, the database design is being illustrated and database was developed for storing this data. The database design that has developed must satisfy the user requirements collected and a good application must fulfil the demand. The database design is the important key towards the success of an application. In the database design, the database must be completed with basic information to allow users easily find the component that they need. Moreover, the basic information about the asset including asset ID, asset type, registration number, asset component and link to 3D model. Thus, there is a need to incorporate all asset information in one database. The database that has been designed enable the users to retrieve the asset information through SQL command. database schemas for storing CityGML data for various database management systems like ORACLE Spatial or PostgreSQL/ PostGIS, using the CityGML XML Schema definition files (Yao et al., 2018). A good database relationship will happen when there is an interaction between the databases in real-time application. Based on an analysis, the more compact database, the more efficient for querying and processing large and complex data structure. The CityGML database scheme is the result of identifying and simplifying the complex CityGML classes and data types.

Two CityGML standards will be incorporated for the database. The standards are Constructions and Building module. The Constructions and Building module is the new standard of CityGML in version 3.0. The new module defines the concept of man-made construction such as Buildings, Bridges, and Tunnels. Building concept will be the focus of discussion. The thematic attributes related to this module are RoofSurface, GroundSurface, or WallSurface. In addition, from the module, the classes from the attribute are defines as a class AbstractConstruction as subclass of AbstractOccupiedSpace as associate with other thematic surfaces. Moreover, Buildings are defined as subclasses of class AbstractConstruction. Application schema of CityGML is identified by the gml:id attribute and FME AttributeCreator transformer is used as shown in Figure 9.

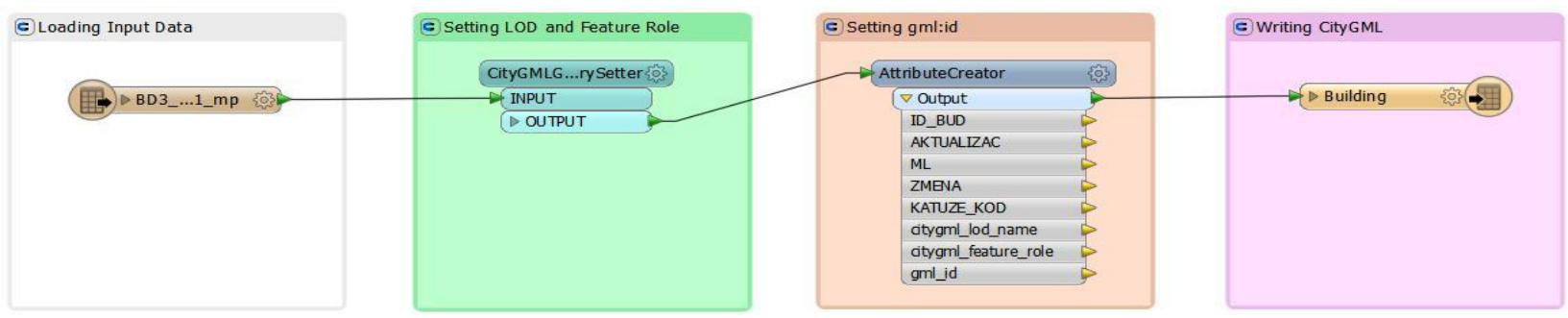

Figure 9: The Trasformation Scheme for Buildings. (Source: Janecka, 2019)

The designing of 3D database that integrated with the MySPATA will be the new improvement and development for asset management in Malaysia. 3D database design will become the core concept for implementation of smart city. As related to smart city, the design of database is based on virtual 3D city model. These models contain 3D data about urban objects such as buildings, roads and waterways where the data are collected, maintained and used in applications for urban planning and environmental simulations (Koukofikis et al., 2018). From this 3D city models, a 3D city database will be produced.

3D City Database is free Geo database to store, represent, and manage virtual 3D city models on top of a standard spatial relation database (OCG, 2020). Due to the large size and complexity of the sometimes country-wide 3D geospatial data, the GIS software vendors and service providers face many challenges when building 3D spatial data infrastructures for realizing the efficient storage, analysis, management, interaction, and visualization of the 3D city models based on the CityGML standard (Yao et al., 2018). The mapping and creation of database design allow to map the relation of database tables based on CityGML data model. Since CityGML is a GML application schema, these software systems are able to automatically create

\subsection{Implementation of 3D Asset Management Using CityGML Standard}

3D city models are used as integrated information representing the urban entities along their spatial, semantic and visual properties. The city models are usually created to maintain the full coverage of entire cities. It can be clustered and quantified using spatial vector data approach (Azri et al., 2015). On the other hand, 3D models can be used to organize different types of data and sensors within Smart City project. Open Geospatial Consortium (OCG) has issued the CityGML standard. The CityGML defines a feature catalogue and data model for 3D topographic elements.

3D asset management is a new concept introduced to the world. With the current technologies, the asset management should not be handled manually. 3D concept has been introducing to the asset management for more efficient data organizing and maintenance. Current practice has proved that the asset management is time consuming, bland and open to human erroras a consequence of paper-dependant and manual inspection practise (Hajek et al., 2018). So, there is a need to understand the 
structure of 3D and how it integrates with asset management system as the process is noticeably challenging (Sandra $\mathrm{T}$. Matarneh, 2019). In local authorities, this inefficiency is affecting other authorities' work performance where in order to improve in revenue, it must improve the management of assets, considerably on immovable assets (Berahim et al., 2015).

The 3D models can be developed from several data sources such as airborne LiDAR, mobile LiDAR, terrestrial laser scanning and any other data collection method. Meanwhile for attribute information, it can be collected from the agencies or asset's owner. The main object classes that need to be extracted during data collection are ground, building, vegetation and other required data. In this study, data are generated in the LAS files. 3D models will be generated using the output file from LiDAR and ready to be converted into CityGML format. The information on each model will be populated into 3DCityDB using PostgresSQL that utilizes CityGML Scheme. The 3D City Database (3DCityDB) is a free Open Source package consisting of a database schema and a set of software tools to import, manage, analyze, visualize, and export virtual 3D city models according to the CityGML standard. 3DCityDB is in use in the real life production systems in many places around the world and is also being used in a number of research projects (Geoinformatics, 2015). Therefore, with the help of 3DCityDB, the asset information and 3D models are being utilized into database.

The development of 3D city model is being visualized with the five major components below. They are Database Server - that hosting and manage 2D and 3D spatial datasets, Web Services publish and handling data request from web sockets, 3D Web Clients - a platform to visualize and interact with the $3 \mathrm{D}$, Desktop GIS - Direct data access, update and edit to the database, and Existing Datasets - new or existing datasets. The Figure 10 shows the visualization of 3D model within Web Client Cesium (Abdul Rahman et al., 2019).

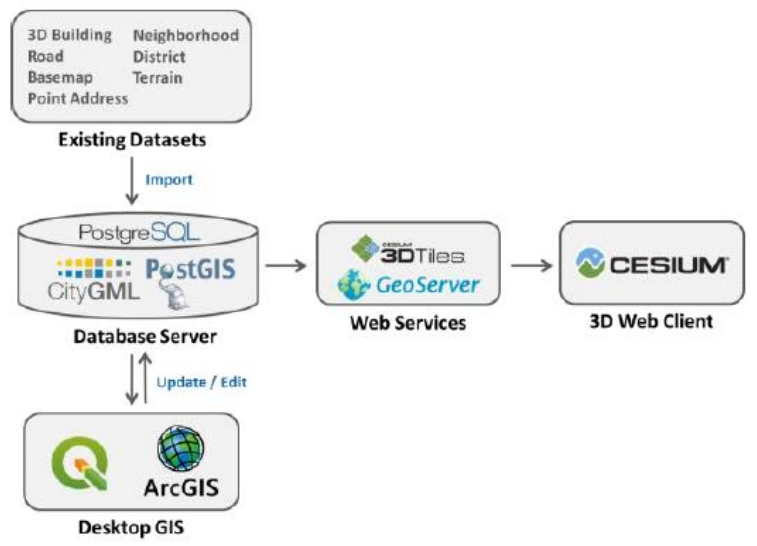

Figure 10: An integrated schematic diagram of the data flow.

\section{CONCLUSION}

Smart City is an application integrated with the current technology for the improvement of city management. City management involves the management of infrastructures, that is, the management of all data used in decision-making, including management of civil engineering and environmental data, topographical data, geotechnical and geological data, asset management, management of current or planned work, space management, risk management, etc. Consequently, the 3D city model must be analysed holistically and integrate all physical systems, social parameters, regulations, and more (Lafioune and St-Jacques, 2020). Thus, 3D asset management is a suitable start for Smart City application.

3D asset management is not a new approach but has been increasing in demand towards efficient and sustainable management. In Malaysia, an electronic-based asset management system is being made prior to the inefficiency on asset management system. The problem is that assets are still managed using conventional inventory method as the assets are being coded and entered into asset plan. In making complex decision like multi-criteria analysis, the use of computerized decisionbased may ease the process (Mohd et al., 2016). In the face of issues that are constantly increasing in the scope and complexity, the solutions proffered to aid in decision-making are also becoming ever smarter. These include, for example, the block chain, building information modelling (BIM), Geographic Information System (GIS), the smart city and digital 3D city models (Lafioune and St-Jacques, 2020).

Moreover, MySPATA system does not integrate with 3D model making the managing of asset is difficult for the authorities to locate actual position of the asset. In our current existing technology, 3D asset management system is important for locating and monitoring in asset management. Therefore, for the future of managing asset, the asset management should be integrated with the 3D models using CityGML standard based on MySPATA.

\section{ACKNOWLEDGEMENTS}

This research was partially funded by UTM Research University Grant, Vot Q.J130000.2652.15J95 and Vot Q.J130000.3552.06G41.

\section{REFERENCES}

Abdul Rahman, A., Rashidan, H., Musliman, I. A., Buyuksalih, G., Bayburt, S. \& Baskaraca, P. 2019. 3d Geospatial Database Schema for Istanbul 3D City Model. ISPRS - International Archives of the Photogrammetry, Remote Sensing and Spatial Information Sciences, XLII-4/W16, 11-16.

Akula, M., Lipman, R.R., Franaszek, M., Saidi, K.S., Cheok, G.S., Kamat, V.R., 2013. Real-time Drill Monitoring and Control using Building Information Models Augmented with 3D Imaging Data. Automation in Construction 36, 1-15.

Arifin, A. B. M. 2020. Aset Tidak Alih [Online]. Laman Portal Rasmi Politeknik Melaka. Available: http://www.polimelaka.edu.my/portalpmk/index.php/en/201603-08-08-01-35/2016-08-16-00-11-02/aset-tak-alih [Accessed $6 / 7 / 2020]$.

ASSETWORKS. 2018. What is a Smart City? [Online]. Available: https://www.assetworks.com/eam/ [Accessed 16/7/2020].

Azri, S., Anton, F., Ujang, U., Mioc, D., Rahman, A.A., 2015. Crisp Clustering Algorithm for 3D Geospatial Vector Data Quantization, Lecture Notes in Geoinformation and Cartography. Springer Verlag, pp. 71-85. 
Azri, S., Ujang, U., Castro, F.A., Abdul Rahman, A., Mioc, D., 2016. Classified and clustered data constellation: An efficient approach of 3D urban data management. ISPRS Journal of Photogrammetry and Remote Sensing 113, 30-42.

Azri, S., Ujang, U., Abdul Rahman, A., 2018. Dendrogram Clustering for 3D Data Analytics in Smart City. International Archives of Photogrammetry, Remote Sensing and Spatial Informtion Science. XLII-4/W9, 247-253.

Azri, S., Ujang, U., Anton, F., Mioc, D., Rahman, A.A., 2014. Spatial Access Method for Urban Geospatial Database Management: An Efficient Approach of 3D Vector Data Clustering Technique, 9th International Conference on Digital Information Management (ICDIM). IEEE, Bangkok, Thailand.

Barry, J. 2018. 3 Steps to Make GIS Part of A Successful Smart City [Online]. Smartcitiesdives: Industry Dive. Available: Https://Www.Smartcitiesdive.Com/News/3-Steps-To-MakeGis-Part-Of-A-Successful-Smart-City/525245/] [Accessed 6/9/2020].

Berahim, N., Jaafar, M. N. \& Zainudin, A. Z. 2015. An Audit Remark on Malaysian Local Authorities Immovable Asset Management. Journal of Management Research, 7, 218.

Berone, A. 2020. What is an Asset? [Online]. Investopedia. Available: https://www.investopedia.com/terms/a/asset.asp [Accessed 16/7/2020].

Devision, P. M. T. 2019. MySPATA [Online]. IEM. Available: https://www.myiem.org.my/events/eventregistration.aspx $? i d=12$ 818 [Accessed 9/7/2020].

Dewan, S. A. 2004. Pavement Mangement and Asset Management Side-by-Side. 6th International Conference on Managing Pavement.

Geoinformatics, C. O. 2015. 3D City Database for CityGML. Technical University of Munich.

Hajek, P., Md Aslam, H., Ahmad Tarmizi, H., Han, A. L., Kristiawan, S., Chan, W. T., Ismail, M. B., Gan, B. S., Sriravindrarajah, R. \& Hidayat, B. A. 2018. Intelligent BIM record model for effective asset management of constructed facility. MATEC Web of Conferences, 195, 06004.

Janečka, K. 2019. Transformation of 3D geospatial data into CityGML - a case of Prague. Reports on Geodesy and Geoinformatics, 107, 41-48.

JPAK 2018. Manual Pengguna MySPATA.

Kolbe, T. H. 2019. 3D City Modelling and CityGML 3.0.

Koukofikis, A., Coors, V. \& Gutbell, R. 2018. Interoperable Visualization of 3d City Models Using Ogc's Standard 3d Portrayal Service. ISPRS Annals of Photogrammetry, Remote Sensing and Spatial Information Sciences, IV-4, 113-118.

Kutzner, T., Chaturvedi, K. \& Kolbe, T. H. 2020. CityGML 3.0: New Functions Open Up New Applications. PFG - Journal of Photogrammetry, Remote Sensing and Geoinformation Science, $88,43-61$.
Lafioune, N. \& St-Jacques, M. 2020. Towards the creation of a searchable 3D smart city model. Innovation \& Management Review, ahead-of-print.

Leong, K. T. A. K. 2005. The Technology of Asset Management and Maintenance Culture in Ensuring Sustainable Development. Journal of the Malaysia Institute of Planners, 3, 61-70.

Martin, A. 2019. Smart Cities: Moving from Reactive to Predictive Resourse Management [Online]. A SAGA Group Company.

Available: https://www.sageautomation.com/blog/smart-cities-movingfrom-reactive-to-predictive-resource-management [Accessed $16 / 7 / 2020]$.

Mohd, Z.H., Ujang, U., 2016. Integrating Multiple Criteria Evaluation and GIS in Ecotourism: A Review. International Archives of Photogrammetry, Remote Sensing and Spatial Informtion Science. XLII-4/W1, 351-354.

NAIDU, D. S. 2018. GIS Applications to Smart Cities. International Journal of Advanced Multidisciplinary Scientific Research(IJAMSR) Vol 1, 7.

OCG. 2020. 3D CityDB Database [Online]. Technische Universitat Munchen. Available: https://www.3dcitydb.org/3dcitydb/ [Accessed 16/7/2020].

Pan, X., Schröttner, M., Havemann, S., Schiffer, T., Berndt, R., Hecher, M., Fellner, D.W., 2013. A Repository Infrastructure for Working with 3D Assets in Cultural Heritage. International Journal of Heritage in the Digital Era 2, 143-166.

Salleh, S., Ujang, U., 2018. Topological information extraction from buildings in CityGML. IOP Conference Series: Earth and Environmental Science 169, 012088.

Sandra T. Matarneh, M. D.-A., Salam Al-Bizri, Mark Gaterell, Rana Matarneh 2019. Building Information Modelling for Facilities Management: A literature Review and Future Research Directions. Journal of Buiding Engineering, 24.

Saptari, A. Y., Hendriatiningsih, S., Bagaskara, D. \& Apriani, L. 2019. Implementation of Government Asset Management Using Terrestrial Laser Scanner (Tls) as Part of Building Information Modelling (Bim). IIUM Engineering Journal, 20, 49-69.

SHAHROUR, I. 2018. Use of GIS in Smart City Projects. Managing and Visualising Geospatial Data in a User-Friendly Environment [Online]. Available: https://www.giminternational.com/content/article/use-of-gis-in-smart-cityprojects

SmartCity. 2020. Asset Management is an Essential Asset for a Smart City [Online]. Smart City Press. Available: https://www.smartcity.press/smart-city-asset-management/ [Accessed 16/7/2020].

Warner, J. 2014. Asset Life Cycle Mangement [Online]. ReadytoManage. Available: http://blog.readytomanage.com/asset-life-cycle-management/ [Accessed 16/7/2020].

Wenwen Li, M. B. M. F. G. 2020. Real-Time GIS for Smart Cities. International Journal of Geographical Information Science, 32, 311-324. 
The International Archives of the Photogrammetry, Remote Sensing and Spatial Information Sciences, Volume XLIV-4/W3-2020, 2020 5th International Conference on Smart City Applications, 7-8 October 2020, Virtual Safranbolu, Turkey (online)

Wessing, T. 2017. Smart Cities, Digital Assets and BIM [Online]. Available: https://www.taylorwessing.com/download/articlesmart-cities-digital-assets-and-bim.html [Accessed 16/7/2020].

Wikipedia. 2020. Asset Managemet [Online]. Wikipedia. Available: https://en.wikipedia.org/wiki/Asset_management [Accessed 16/7/2020]

Yao, Z., Nagel, C., Kunde, F., Hudra, G., Willkomm, P., Donaubauer, A., Adolphi, T. \& Kolbe, T. H. 2018. 3DCityDB a $3 \mathrm{D}$ geodatabase solution for the management, analysis, and visualization of semantic 3D city models based on CityGML. Open Geospatial Data, Software and Standards, 3.

Yusoff, I.M., Ujang, U., Rahman, A.A., Katimon, A., Ismail, W.R., 2011. Influence of georeference for saturated excess overland flow modelling using 3D volumetric soft geo-objects. Computers \& Geosciences 37, 598-609. 
APPENDIX A: Building Module (Source: Kutzer et al.,2020)

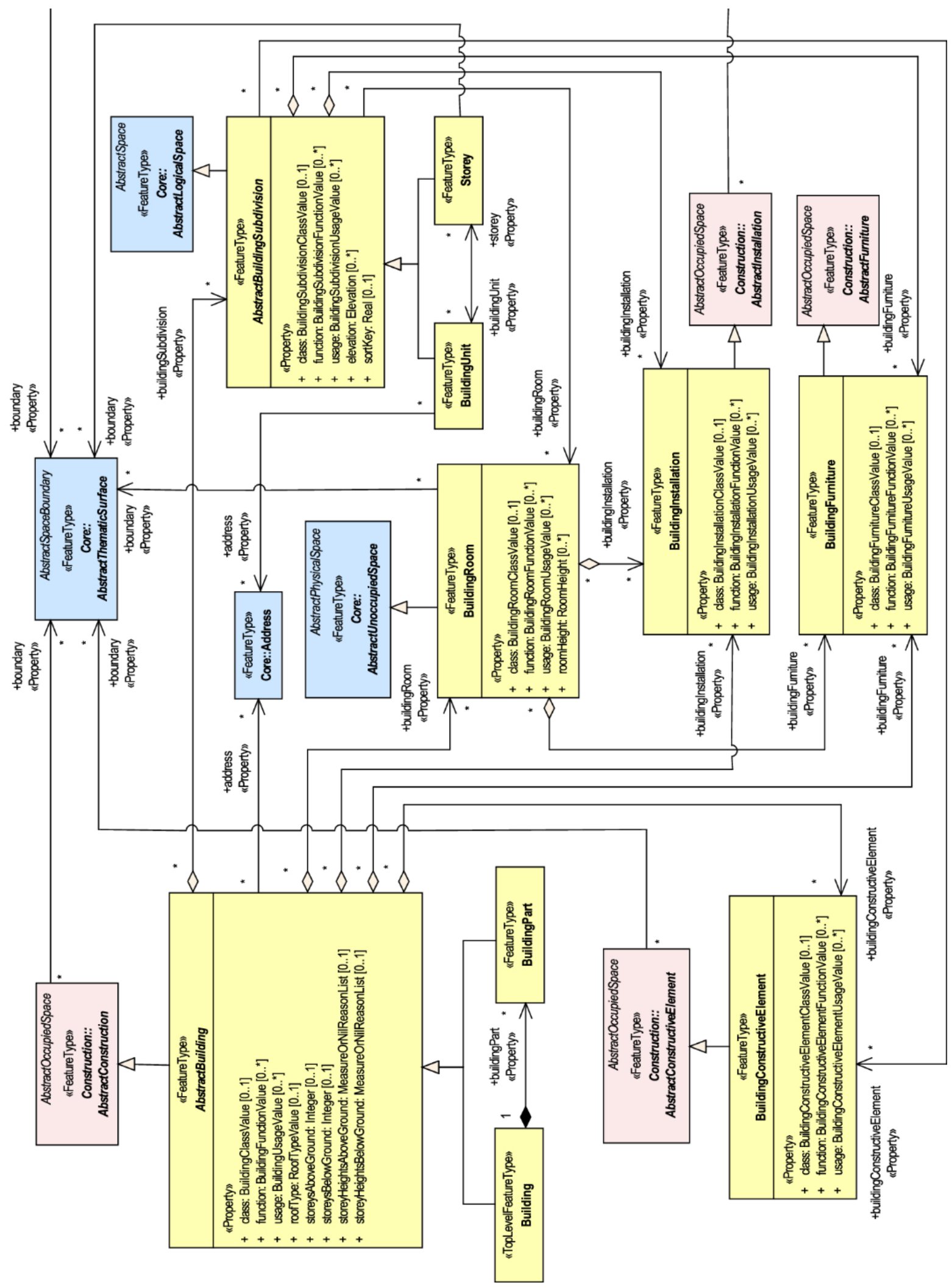

